This document is the accepted manuscript version of the following article:

Ostrom, N. E., Gandhi, H., Coplen, T. B., Toyoda, S., Böhlke, J. K., Brand, W. A., ... Yoshida, N. (2018). Preliminary assessment of stable nitrogen and oxygen isotopic composition of USGS51 and USGS52 nitrous oxide reference gases and perspectives on calibration needs. Rapid Communications in Mass Spectrometry, 32(15), 1207-1214. https://doi.org/10.1002/rcm.8157

\title{
Preliminary assessment of stable nitrogen and oxygen isotopic composition of USGS51 and USGS52 nitrous oxide reference gases and perspectives on calibration needs
}

Nathaniel E. Ostrom ${ }^{1 *}$, Hasand Gandhi' ${ }^{1}$, Tyler B. Coplen² ${ }^{2}$ Sakae Toyoda ${ }^{3}$, J.K. Böhlke², Willi A. Brand ${ }^{4}$, Karen L. Casciotti ${ }^{5}$, Jens Dyckmans ${ }^{6}$, Anette Giesemann ${ }^{7}$, Joachim Mohn ${ }^{8}$, Reinhard Well ${ }^{7}$, Longfei $\mathrm{Yu}^{8}$, and Naohiro Yoshida ${ }^{3,9}$

${ }^{1}$ Department of Integrative Biology and DOE Great Lakes Bioenergy Research Institute, Michigan State University, East Lansing, MI, USA

${ }^{2}$ U.S. Geological Survey, 431 National Center, Reston, VA, USA

${ }^{3}$ Department of Chemical Science and Engineering, School of Materials and Chemical Technology, Tokyo Institute of Technology, Yokohama 226-8502, Japan

${ }^{4}$ Max-Planck-Institute for Biogeochemistry, Beutenberg Campus, P.O. Box 100164, 07701 Jena, Germany

${ }^{5}$ Department of Earth System Science, Stanford University, Stanford, CA, USA

${ }^{6}$ Centre for Stable Isotope Research and Analysis, Büsgen Institute, Georg-August

${ }^{7}$ University Göttingen, Göttingen, Germany

Thünen Institut of Climate-Smart Agriculture, Braunschweig, Germany

${ }^{8}$ Laboratory for Air Pollution \& Environmental Technology, Empa, Überlandstr. 129, CH-8600 Dübendorf, Switzerland

${ }^{9}$ Earth-Life Science Institute, Tokyo Institute of Technology, Tokyo 152-8550, Japan

* Corresponding author

\begin{abstract}
:
RATIONAL: Despite a long history and growing interest in isotopic analyses of $\mathrm{N}_{2} \mathrm{O}$, there is a lack of isotopically characterized $\mathrm{N}_{2} \mathrm{O}$ isotopic reference materials (standards) to enable normalization and reporting of isotope-delta values. Here we report the isotopic characterization of two pure $\mathrm{N}_{2} \mathrm{O}$ gas reference materials, USGS51 and USGS52, which are now available for laboratory calibration (https://isotopes.usgs.gov/lab/referencematerials.html).
\end{abstract}

METHODS: A total of 400 sealed borosilicate glass tubes of each $\mathrm{N}_{2} \mathrm{O}$ reference gas were prepared from a single gas filling of a high vacuum line. We demonstrated isotopic homogeneity via dual-inlet isotope-ratio mass spectrometry. Isotopic analyses of these reference materials were obtained from eight laboratories to evaluate interlaboratory variation and provide preliminary isotopic characterization of $\delta^{15} \mathrm{~N}, \delta^{18} \mathrm{O}, \delta^{15} \mathrm{~N}^{\alpha}, \delta^{15} \mathrm{~N}^{\beta}$, and site preference $\left(S_{\mathrm{P}}\right)$ measurements.

RESULTS: Isotopic homogeneity of USGS51 and USGS52 was demonstrated for both USGS51 and USGS52 by one-sigma standard deviations associated with the determinations of $\delta^{15} \mathrm{~N}, \delta^{18} 0, \delta^{15} \mathrm{~N}^{\alpha}, \delta^{15} \mathrm{~N}^{\beta}$ and $S_{\mathrm{P}}$ of $0.12 \mathrm{mUr}$ or better. The onesigma standard deviations of $S_{\mathrm{P}}$ measurements of USGS51 and USGS52 reported by eight laboratories participating in the interlaboratory comparison were 1.27 and $1.78 \mathrm{mUr}$, respectively. 
CONCLUSIONS: The agreement of isotope-delta values obtained in the interlaboratory comparison was not sufficient to provide reliable accurate isotopemeasurement values for USGS51 and USGS52. We propose that provisional values for the isotopic composition of USGS51 and USGS52 determined at the Tokyo Institute of Technology can be adopted for normalizing and reporting sample data until further refinements are achieved through additional calibration efforts.

For a remarkably simple molecule, consisting of only two elements and three atoms, there is a surprising degree of isotopic complexity in nitrous oxide $\left(\mathrm{N}_{2} \mathrm{O}\right)$. ${ }^{[1]}$ The two stable isotopes of nitrogen and three stable isotopes of oxygen combine to form 12 isotopic molecules or isotopocules. This coupled with the asymmetrical structure of $\mathrm{N}_{2} \mathrm{O}(\mathrm{N}-\mathrm{N}-\mathrm{O})$ means that the $\mathrm{N}_{2} \mathrm{O}$ molecule contains bulk $\left(\delta^{15} \mathrm{~N}, \delta^{18} \mathrm{O}\right.$, $\left.\delta^{17} 0\right)$, mass independent $\left(\Delta^{17} \mathrm{O}\right)$, site specific $\left({ }^{15} \mathrm{~N}^{14} \mathrm{~N}^{16} \mathrm{O}\right.$ vs. $\left.{ }^{14} \mathrm{~N}^{15} \mathrm{~N}^{16} \mathrm{O}\right)$, and clumped (e.g. ${ }^{15} \mathrm{~N}^{14} \mathrm{~N}^{18} \mathrm{O}$ ) isotopic information. Strong interest in this greenhouse gas, as well as advances in technology that have lowered instrument costs and improved sample throughput, have resulted in a doubling of publications related to the isotopic composition of $\mathrm{N}_{2} \mathrm{O}$ over the last 20 years. ${ }^{[1]}$ This has been facilitated, in part, by the fact that traditional mass spectrometric approaches to the determination of isotope ratios are now being supplemented by laser-based spectroscopy.[2,3] Additionally, the recent development of double-focusing mass spectrometers for precise stable isotope analyses of rare isotopocules with high mass resolution and good sensitivity now enable clumped isotopic analysis of $\mathrm{N}_{2} \mathrm{O} .[4,5]$

Despite the strong interest in and long history of isotopic analyses of $\mathrm{N}_{2} \mathrm{O},[6,7]$ there is a lack of isotopically characterized $\mathrm{N}_{2} \mathrm{O}$ isotopic reference materials (standards) to enable normalization ${ }^{[8]}$ and reporting of compatible isotope-delta values (within analytical uncertainty) from different laboratories worldwide. Thus, while reported isotope-delta values for $\mathrm{N}_{2} \mathrm{O}$ may be consistent within one laboratory, disparity among laboratories can be substantial. This was recently demonstrated by an $11 \mathrm{mUr}$ range ${ }^{[9]}$ in the quantity site preference (symbol $S_{\mathrm{P}}$ ), which we define as the difference in $\delta^{15} \mathrm{~N}$ values between the central, $\alpha$, and outer, $\beta$, nitrogen atoms in a $\mathrm{N}_{2} \mathrm{O}$ sample. Non-uniformity of isotopic measurements between laboratories may be a significant factor compromising global assessments of $\mathrm{N}_{2} \mathrm{O}$ sources and sinks based on stable isotope data.[10] Relative isotope ratios expressed as delta values are commonly reported in units of per mil (symbol \%o) that are not considered acceptable in the International System of Units.[11] In this study, we substitute the term urey (symbol Ur) for the delta unit as suggested by Brand and Coplen[12], such that one milliurey $(0.001)$ equals $1 \%$. A delta value in the traditional form of $-25 \%$, for example, can be expressed as -25 mUr. In addition, although the symbol SP is commonly used in the scientific literature for site preference; we use $S_{\mathrm{P}}$ because symbols of quantities in the International System of Units (SI) should be a single character (with desired superscripts or subscripts).[13] Furthermore, symbols of quantities should be printed in italic font. 
With this article we report the isotopic characterization of two pure $\mathrm{N}_{2} \mathrm{O}$ gas reference materials, USGS51 and USGS52, which are now available in sealed borosilicate glass tubes for laboratory calibration (https://isotopes.usgs.gov/lab/referencematerials.html). We demonstrated isotopic homogeneity via dual-inlet isotope-ratio mass spectrometry (DI-IRMS). Further, we present data on isotopic analyses of these isotopic reference materials from eight laboratories to evaluate interlaboratory variation and provide preliminary isotopic characterization. Ultimately, there is a need for (1) additional pure $\mathrm{N}_{2} \mathrm{O}$ gas isotopic reference materials with a wider range of isotopic compositions, (2) additional calibration efforts to improve accuracy of the isotope values assigned to these isotopic reference materials, and (3) development of large-volume standards in an air matrix that will be of use for calibration of spectroscopic instruments for analyses of $\mathrm{N}_{2} \mathrm{O}$ in air.

\section{METHODS}

USGS51 was prepared from Air Products (Trexlertown, Pennsylvania, USA) VLSI grade $\mathrm{N}_{2} \mathrm{O}$ (99.9994 \%). USGS52 was prepared from Air Products USP grade $\mathrm{N}_{2} \mathrm{O}$. Aliquot preparation occurred within a high-vacuum glass manifold consisting of 20 0.5-L glass reservoirs, following the procedure of Coplen and Kendall.[14] By opening appropriate manifold stopcocks, the 20 reservoirs were connected in series with a diaphragm pump so the gas could be cycled through the reservoirs and isotopically homogenized. Stopcocks were manipulated to expand the gas from each of the 20 reservoirs into a manifold having ports for $206-\mathrm{mm}$ borosilicate glass tubes and a mercury piston for gas homogenization. Thus, 400 glass tubes containing identical aliquots of a gas were prepared from a single filling of the high vacuum line. Procedures are described in detail in Coplen and Kendall [14] and are summarized briefly here: (1) evacuate the entire vacuum manifold, (2) fill the entire manifold with $\mathrm{N}_{2} \mathrm{O}$ from the tank of interest to a pressure of approximately $70 \mathrm{kPa}$ for a period of 5 min to treat the surface of the glass manifold, (3) evacuate $\mathrm{N}_{2} \mathrm{O}$, (4) refill the manifold with $\mathrm{N}_{2} \mathrm{O}$ from the sample tank to a pressure of $70 \mathrm{kPa}$, (5) cycle the $\mathrm{N}_{2} \mathrm{O}$ through the 200.5 -L glass reservoirs with a diaphragm pump for $30 \mathrm{~min}$ to isotopically homogenize the $\mathrm{N}_{2} \mathrm{O},(6)$ isolate the $\mathrm{N}_{2} \mathrm{O}$ in the 200.5 - $\mathrm{L}$ glass volumes by closing stopcocks on each volume, (7) expand the $\mathrm{N}_{2} \mathrm{O}$ in the first 0.5-L glass volume into the manifold containing $206-\mathrm{mm}$ borosilicate glass tubes, each with a line volume of about $40 \mathrm{~mL},(8)$ homogenize the $\mathrm{N}_{2} \mathrm{O}$ by cycling the mercury piston pump for $30 \mathrm{~min}$, (9) isolate the 20 stopcocks on the $40 \mathrm{~mL}$ volumes, (10) cryogenically condense the $\mathrm{N}_{2} \mathrm{O}$ into each of the 20 borosilicate glass tubes, (11) seal each of the 20 tubes one-by-one with a torch, evacuating non-condensable gases with a mercury diffusion pump during sealing, and (12) repeat steps 7 through 11 for the $\mathrm{N}_{2} \mathrm{O}$ in the other 190.5 -L glass reservoirs. Each of the 400 glass tubes is expected to contain approximately $300 \mu \mathrm{mol}$ of $\mathrm{N}_{2} \mathrm{O}$ in a volume of approximately $45 \mathrm{~mL}$. 
To confirm isotopic homogeneity, one tube from each set of 20, and multiple tubes from a few of the sets, were analyzed for $\delta^{15} \mathrm{~N}, \delta^{18} 0, \delta^{15} \mathrm{~N}^{\alpha}, \delta^{15} \mathrm{~N}^{\beta}$ and $S_{\mathrm{P}}$ by dual-inlet isotope-ratio mass spectrometry (DI-IRMS) using an Elementar Isoprime mass spectrometer (Elementar Analysensysteme GmbH Elementar-Straße 1, 63505 Langenselbold) at Michigan State University (Table 1; Laboratory 4 in Table 2). The $\delta^{17} \mathrm{O}$ values and clumped isotopic compositions of USGS51 and USGS52 were not evaluated. Mass-overlap corrections were performed using the approach of Toyoda and Yoshida.[15] The $\delta^{15} \mathrm{~N}^{\alpha}$ value was determined from the $\mathrm{m} / z 31$ to $\mathrm{m} / z 30$ ratio of the $\mathrm{NO}^{+}$fragment ion. The $\delta^{15} \mathrm{~N}^{\beta}$ and $S_{\mathrm{p}}$ values are calculated based on the following equations:

$$
\delta^{15} \mathrm{~N}=\left(\delta^{15} \mathrm{~N}^{\alpha}+\delta^{15} \mathrm{~N}^{\beta}\right) / 2
$$

and

$$
S_{\mathrm{P}}=\delta^{15} \mathrm{~N}^{\alpha}-\delta^{15} \mathrm{~N}^{\beta}
$$

Two glass tubes were selected at random and sent to eight laboratories for isotopic analysis (Table 2). Laboratory 1 determined the $\delta^{15} \mathrm{~N}, \delta^{15} \mathrm{~N}^{\alpha}, \delta^{15} \mathrm{~N}^{\beta}, \delta^{18} 0$ and $S_{\mathrm{P}}$ values within the dual inlet of a MAT252 mass spectrometer (Thermo Fisher Scientific Inc., Waltham MA USA) in comparison to a isotopically characterized laboratory tank of pure $\mathrm{N}_{2} \mathrm{O}$. The $\delta^{15} \mathrm{~N}, \delta^{15} \mathrm{~N}^{\alpha}$ and $\delta^{15} \mathrm{~N}^{\beta}$ values of the local reference gas were anchored to atmospheric $\mathrm{N}_{2}\left(\right.$ Air- $\left.\mathrm{N}_{2}\right)$ scale by ammonium nitrate decomposition,[15] whereas the $\delta^{18} 0$ value was anchored to Vienna Standard Mean Ocean Water (VSMOW) standard by converting $\mathrm{N}_{2} \mathrm{O}$ to $\mathrm{CO}_{2}$ with graphite and platinum foil (Yoshida, unpublished).[16] Laboratory 2 performed isotopic analyses by mid-infrared quantum cascade laser absorption spectroscopy in an air matrix with a volume fraction of approximately $60 \mathrm{ppm}$ against internal reference gases previously analyzed by Laboratory 1 . $^{[2]}$ Laboratory 3 determined the isotopic composition of USGS51 and USGS52 using a PRECON (Thermo Fisher Scientific Inc., Waltham MA USA) [17] sample introduction system interfaced to Thermo Fisher Scientific Deltaplus XP isotope-ratio mass spectrometer. Both gases were diluted and analyzed in $\mathrm{N}_{2}$, at a volume fraction of $\mathrm{N}_{2} \mathrm{O}$ of $10 \mathrm{ppm}$. Isotope-delta values were normalized using the secondary standards of Laboratory 6. Laboratory 4 determined the isotopic composition of USGS51 and USGS52 using a dual-inlet interfaced to an Elementar Isoprime mass spectrometer in comparison to a laboratory compressed tank of pure $\mathrm{N}_{2} \mathrm{O}$ calibrated by Laboratory 1 . Laboratory 5 measured the bulk $\delta^{15} \mathrm{~N}, \delta^{18} 0$ values, as well as $\delta^{15} \mathrm{~N}^{\alpha}, \delta^{15} \mathrm{~N}^{\beta}$, and $S_{\mathrm{P}}$ values by dualinlet isotope-ratio mass spectrometry on a Thermo Finnigan Deltaplus XP (Thermo Fisher Scientific Inc., Waltham MA USA). An aliquot of the reference gas used in the analysis was calibrated to the Air- $\mathrm{N}_{2}$ reference scale for determination of bulk $\delta^{15} \mathrm{~N}$, $\delta^{15} \mathrm{~N}^{\alpha}$, and $\delta^{15} \mathrm{~N}^{\beta}$ values, and to the $\delta^{18} \mathrm{O}$ VSMOW isotope-delta scale by Laboratory 
1. Laboratory 6 determined the isotopic composition of USGS51 and USGS52 in continuous flow mode using a Delta V PLUS mass spectrometer connected to a Precon and a Trace GC (Thermo Fisher Scientific Inc.). Both gases were diluted and analyzed in synthetic air or $\mathrm{N}_{2}$, respectively, at a volume fraction of $\mathrm{N}_{2} \mathrm{O}$ of 10 ppm. ${ }^{[18]}$ Isotope-delta values were normalized using two secondary standards differing in $S_{\mathrm{p}}$ value (-2.14 mUr and $18.93 \mathrm{mUr}$, respectively), both calibrated by Laboratory 1 . Laboratory 7 measured bulk $\delta^{15} \mathrm{~N}$ by dual-inlet isotope-ratio mass spectrometry via analyses of $\mathrm{N}_{2}$ produced by off-line conversion of $\mathrm{N}_{2} \mathrm{O}$ and ammonium sulfate reference materials with $\mathrm{Cu}+\mathrm{CuO} ; \mathrm{N}_{2} \mathrm{O}$ data were normalized to an assumed $\delta^{15} \mathrm{~N}$ value of $+0.43 \mathrm{mUr}$ for IAEA-N1 (Table 3). Laboratory 8 evaluated the isotopic composition of the two USGS standards with the dual inlet of a Thermo Fisher Scientific MAT252 mass spectrometer in comparison to a local tank reference gas. Only Laboratory 1 characterized its laboratory standards by ammonium nitrate decomposition. All other laboratories obtained calibrations by exchange of standards with Laboratory 1.

\section{RESULTS}

Isotopic homogeneity in USGS51 and USGS52 was demonstrated both within sets of 20 tubes (12-A vs. 12-B and 15-A vs. 15-B for USGS51 and 1A-C for USGS52) and across sets of 20 glass tubes (Table 1). The one-sigma standard deviations associated with the determinations of $\delta^{15} \mathrm{~N}, \delta^{18} 0, \delta^{15} \mathrm{~N}^{\alpha}, \delta^{15} \mathrm{~N}^{\beta}$ and $S_{\mathrm{P}}$ values across all aliquots of USGS51 was $0.06 \mathrm{mUr}$ or better; that for USGS52 was $0.12 \mathrm{mUr}$ or better, which suggests slightly greater heterogeneity in USGS52. For each gas aliquot the standard deviation was greater for $S_{\mathrm{P}}$ than other isotope quantities measured, but this is not surprising as the quantity $S_{\mathrm{P}}$ is calculated from two isotope ratios (Equation 2). Nonetheless, the overall repeatability for all isotope measurements was better than that typically reported for measurements by gas chromatography interfaced to a mass spectrometer or for spectroscopic instruments.[2,19]

The one-sigma standard deviations of $\delta^{15} \mathrm{~N}$ measurements of USGS51 and USGS52 reported by eight laboratories are 0.21 and $0.25 \mathrm{mUr}$, respectively (Table 2 ). The one-sigma standard deviations of $S_{\mathrm{p}}$ measurements of USGS51 and USGS52 are 1.27 and $1.78 \mathrm{mUr}$, respectively (Table 2). The total range in $S_{\mathrm{p}}$ values of USGS52 was $5.1 \mathrm{mUr}$, which represents an improvement in comparison to a prior interlaboratory calibration exercise that reported an 11-mUr range. ${ }^{[9]}$ To verify accuracy in $\delta^{15} \mathrm{~N}$ Laboratory 7 converted the IAEA-N1 and IAEA-N2 ammonium sulfate standards, USGS51, USGS52 and internal laboratory $\mathrm{N}_{2} \mathrm{O}$ standards from Laboratories 1, 4 and 8, to $\mathrm{N}_{2}$ and performed isotopic analysis in comparison to the NSVEC $\mathrm{N}_{2}$ secondary standard (Table 3). The results, shown as a difference in $\delta^{15} \mathrm{~N}$ between the measured and reported values cluster in two groups near $0.0 \mathrm{mUr}$ (IAEA-N1, IAEA-N2, NSVEC and NINO) and approximately -0.3 mUr (USGS51, USGS52, TokyoTech and MSU-C). 


\section{DISCUSSION}

\section{Evaluation of USGS51 and USGS52 reference materials}

The accurate assessment of isotope-delta values and other isotope measurements is a fundamental challenge to the isotope biogeochemistry research community. A small set of primary international measurement standards has been identified to anchor $\delta$ scales and enable comparable isotope data sets to be generated by laboratories across the globe.[20] For $\mathrm{N}_{2} \mathrm{O}$ these primary standards are Air- $\mathrm{N}_{2}$ and VSMOW for $\delta^{15} \mathrm{~N}$ and $\delta^{18} 0$ measurements, respectively. Numerous secondary isotopic reference materials have been established that are chemically similar to various materials being analyzed (e.g. sulfate, nitrate, and hair) to permit consistency in isotopic measurements involving various sample preparation and handling protocols. While seeming inherently straightforward, accuracy continues to be surprising elusive. For example, analytical precision in the ${ }^{13} \mathrm{C} /{ }^{12} \mathrm{C}$ ratio of calcite has been reported to $3 \mu \mathrm{Ur}$, yet uncertainty in the absolute value of the primary carbon isotope standard, NBS 19, is 2.5 mUr.[20,21,22] While reducing uncertainty in the isotopic compositions of primary isotope standards continues to be an ongoing effort, it is essential that consistency of relative isotope-ratio measurements among laboratories be obtained.

The lack of secondary isotopic reference materials for $\mathrm{N}_{2} \mathrm{O}$ measurements has meant that laboratories have had to develop internal calibration protocols or exchange standards with a laboratory that has performed calibration by ammonium nitrate decomposition or other method. The bulk $\delta^{15} \mathrm{~N}, \delta^{18} \mathrm{O}$, and $\delta^{17} \mathrm{O}$ values of $\mathrm{N}_{2} \mathrm{O}$ can be determined by analyzing $\mathrm{N}_{2}$ and/or $\mathrm{O}_{2}$ produced by decomposition or reduction of $\mathrm{N}_{2} \mathrm{O}$ using hot copper ${ }^{[23]}$, gold tubes ${ }^{[24,25]}$, microwave discharge[26], or carbon rods wrapped with platinum wire at high temperature.[27] Obtaining precise site-specific $\delta^{15} \mathrm{~N}$ values for $\mathrm{N}_{2} \mathrm{O}$ has been challenging and calibration schemes have been based primarily on $\mathrm{N}_{2} \mathrm{O}$ produced by decomposition of ammonium nitrate during which the $\alpha$ nitrogen atom is derived from nitrate and the $\beta$ atom from ammonium. ${ }^{[15]}$ If the ammonium and nitrate $\delta^{15} \mathrm{~N}$ values in ammonium nitrate are known, then $\mathrm{N}_{2} \mathrm{O}$ can be generated with known $\delta^{15} \mathrm{~N}^{\alpha}$ and $\delta^{15} \mathrm{~N}^{\beta}$ values that are anchored to the Air- $\mathrm{N}_{2}$ nitrogen-isotope scale. Unfortunately, this reaction is difficult to reproduce, potentially explosive, and non-quantitative. ${ }^{[3,15,28,29]}$ Consequently, few laboratories have used this approach for calibration. A recent detailed assessment of this calibration approach has shown that the $\alpha$ and $\beta$ nitrogen atoms fractionate distinctly during ammonium nitrate decomposition. ${ }^{[29]}$ Given the challenge of accurately conducting ammonium nitrate decomposition, many laboratories have calibrated internal $\mathrm{N}_{2} \mathrm{O}$ standards by exchange with previously calibrated laboratories. In particular, for $\delta^{15} \mathrm{~N}^{\alpha}$ and $\delta^{15} \mathrm{~N}^{\beta}$ determinations, and hence $S_{\mathrm{P}}$ determination, $\mathrm{N}_{2} \mathrm{O}$ isotopic calibration has primarily been obtained by exchange with the laboratory of Naohiro Yoshida and Sakae Toyoda at Tokyo Institute of Technology.

With the introduction of USGS51 and USGS52, the first pair of $\mathrm{N}_{2} \mathrm{O}$ secondary reference materials is now widely available as pure gases containing approximately 
$300 \mu \mathrm{mol}$ of gas in glass tubes. We demonstrate isotopic homogeneity across aliquots with an uncertainty (one standard deviation) of $0.12 \mathrm{mUr}$ or better for $\delta^{15} \mathrm{~N}$, $\delta^{18} 0, \delta^{15} \mathrm{~N}^{\alpha}, \delta^{15} \mathrm{~N}^{\beta}$ and $S_{\mathrm{p}}$ values (Table 1). Results from analyses of USGS51 and USGS52 by eight laboratories exhibited uncertainty that ranged from $0.21 \mathrm{mUr}$ for $\delta^{15} \mathrm{~N}$ to $1.78 \mathrm{mUr}$ for $S_{\mathrm{P}}$ (Table 2). These analyses were performed by three different approaches: spectroscopic (Laboratory 2), continuous flow - gas chromatography isotope ratio mass spectrometry (Laboratory 6) and dual-inlet mass spectrometry (Laboratories 1, 3, 4, 5, 7 and 8) (Table 2). Gas chromatography may not result in complete removal of $\mathrm{O}_{2}$ and $\mathrm{N}_{2}$ and co-elution of these gases with $\mathrm{N}_{2} \mathrm{O}$ may have resulted in some deterioration in reproducibility and accuracy via production of NO within the ion source. Dilution of the pure gas $\mathrm{N}_{2} \mathrm{O}$ standards in He instead of $\mathrm{N}_{2}$ or $\mathrm{O}_{2}$ will likely yield better results. The reproducibility of measurement results for USGS52 is somewhat better than that of USGS51. To rule out contamination, two tests were performed. First, $m / z$ scans of USGS51 and USGS52 were performed and compared-no measurement differences outside measurement error were observed. Second, USGS51 and USGS52 were analyzed against each other with a double focusing, dual-inlet isotope-ratio mass spectrometer having a total ion beam monitor. ${ }^{[30]}$ This instrument compares the total ion beam current of all $\mathrm{m} / \mathrm{z}$ ions with the $m / z 44$ ion beam current. A contamination value of USGS51 of $0.01 \pm 0.02$ percent was measured. Thus, no contamination of USGS51 could be identified and differences in reproducibility may reflect minor differences in sample handling. The larger variability in $S_{\mathrm{p}}$ relative to other isotope ratios reflects the fact that this value is calculated from two isotope ratios and is dependent upon measurement of the NO fragment ion that is lower in abundance than the molecular ion and is affected by rearrangement in the ion source of mass spectrometers.

The uncertainty that we report (Table 2) is sufficiently large that we recognize that additional calibration efforts are needed. For comparison, the standard deviation of reported $\delta^{15} \mathrm{~N}$ values from ten laboratories participating in the isotopic characterization of the NSVEC $\mathrm{N}_{2}$ standard was 0.05 mUr. ${ }^{[31]}$ Nonetheless, the uncertainty reported here for $S_{\mathrm{P}}$ values for USGS51 and USGS52 is smaller than the uncertainty of $4.3 \mathrm{mUr}$ for an interlaboratory analysis of $\mathrm{N}_{2} \mathrm{O}$ standards in air by mass spectrometry with a mixing volume ratio of 90 ppm. ${ }^{[9]}$ Thus, either (1) improvements in precision have occurred since the Mohn et al.[9] study, or (2) precision is more readily obtained, particularly for mass spectrometry, using pure $\mathrm{N}_{2} \mathrm{O}$ than for $\mathrm{N}_{2} \mathrm{O}$ in a matrix of air at elevated concentrations. Nonetheless, we cannot be certain that the average isotope values presented in Table 2 represent accurate isotope-measurement values for USGS51 and USGS52.

Of the eight participating laboratories in the current study, only one indicated calibration of local $\mathrm{N}_{2} \mathrm{O}$ standards by decomposition of ammonium nitrate (Laboratory 1); others were dependent upon exchange of $\mathrm{N}_{2} \mathrm{O}$ standards and calibration data, primarily originating in the laboratory of Naohiro Yoshida at the Tokyo Institute of Technology (Laboratory 1 in Table 2). Such interlaboratory exchanges may be reflected in clustering of $\delta^{15} \mathrm{~N}$ values from several different laboratories near those reported by Laboratory 1 in Table 2 . In contrast, Laboratory 7, which converted $\mathrm{N}_{2} \mathrm{O}$ to $\mathrm{N}_{2}$ and calibrated data against IAEA ammonium sulfate 
reference materials, reported bulk $\delta^{15} \mathrm{~N}$ values approximately $0.2-0.3 \mathrm{mUr}$ more negative than the Laboratory 1 values (Table 3). A similar offset of $0.39 \mathrm{mUr}$ was reported for a tank of medical grade $\mathrm{N}_{2} \mathrm{O}$ analyzed by combustion to $\mathrm{N}_{2}$ in Laboratory 8 and by Laboratory 1.[2] This result suggests that there may be a 0.2-0.3 mUr offset of the USGS standards in $\delta^{15} \mathrm{~N}$. Because not all analyses in this study were calibrated independently and some of the differences are not fully resolved, we conclude that additional analyses and interlaboratory exchanges are needed to obtain more accurate values for the isotopic compositions of USGS51 and USGS52. Analytical methods may include decomposition of a common ammonium nitrate reference material and analysis by multiple laboratories and/or comparison to $\mathrm{N}_{2} \mathrm{O}$ allowed to reach isotopic equilibrium at moderate temperatures. ${ }^{[4]}$ Meanwhile, we suggest that the complete set of values reported by Laboratory 1 (Tokyo Institute of Technology, highlighted in bold type in Table 2) can be used provisionally for normalizing $\mathrm{N}_{2} \mathrm{O}$ isotopic measurements to improve interlaboratory consistency following the reporting guidelines given below.

\section{Reporting of stable-isotope-delta values}

The following recommendations are provided for reporting stable oxygen and nitrogen isotope-delta values[32]:

- The $\delta^{18} 0$ values of all oxygen-bearing substances should be expressed relative to VSMOW-SLAP on a scale where $\delta^{18} \mathrm{O}_{\text {SLAP }}=-55.5 \mathrm{mUr}$ exactly. ${ }^{[33,34]}$ Reporting of $\delta^{18} 0$ values relative to SMOW should be discontinued.[54]

- The $\delta^{15} \mathrm{~N}$ values of all nitrogen-bearing substances should be expressed relative to atmospheric nitrogen gas (Air $\mathrm{N}_{2}$ ). ${ }^{[36]}$

- Authors should report $\delta$ values of internationally distributed (secondary) isotopic reference materials that were assumed for normalization of data for samples of similar chemical composition, as appropriate for the measurement method. Thus, for reporting isotope-delta values of nitrous oxide samples, values assumed for USGS51 and USGS52, or other widely distributed reference gases, should be included in publications. In this manner, readers can re-normalize reported results subsequently when recommended values of reference materials are improved with new techniques.

\section{Future directions}

There is a compelling need for the $\mathrm{N}_{2} \mathrm{O}$ isotope research community to continue calibration efforts, and this should ideally occur with support from funding agencies and in collaboration with international agencies experienced in such measurements (e.g., the IAEA). Because of the isotopic complexity of $\mathrm{N}_{2} \mathrm{O}$, no single calibration effort is likely to be successful, and we envision that this will be a longterm effort consisting of multiple steps. We recommend the establishment of at least 
one secondary ammonium nitrate reference material that can then be used in decomposition experiments to accurately characterize $S_{\mathrm{P}}$ values. The clumped isotopic composition of pure $\mathrm{N}_{2} \mathrm{O}$ reference materials can be evaluated by equilibration with activated alumina at moderate temperatures, ${ }^{[4]}$ and this may be a viable approach for calibration of $S_{\mathrm{p}}$ values. There is a need for common mass overlap corrections in mass spectrometric analysis ${ }^{[3,15]}$ and we encourage publication of spreadsheets to accomplish this task, as was recently done for the isotopic analysis of water by spectroscopic approaches. ${ }^{[37]}$ As mass overlap corrections for $\mathrm{N}_{2} \mathrm{O}$ are complicated and involve assumptions, such as equivalent isotopic fractionation during breakage of $\alpha$ and $\beta$ nitrogen bonds during ionization, spectroscopic approaches may prove useful in evaluating the validity of such assumptions. ${ }^{[1,38]}$ There is a need for additional pure $\mathrm{N}_{2} \mathrm{O}$ gas isotope reference materials because, although USGS51 and USGS52 differ markedly in $S_{\mathrm{P}}$, they are similar in bulk $\delta^{15} \mathrm{~N}$ and $\delta^{18} \mathrm{O}$. Spectroscopic instruments require large volumes of standards with a wide range of isotope values in a matrix similar to samples (typically air) and with concentrations encompassing the samples being analyzed. This is unlikely to be a realistic task for international agencies; however, isotopically characterized tanks of $\mathrm{N}_{2} \mathrm{O}$ in purified air could be provided by a well-calibrated laboratory. The research community should not underestimate the challenge of such calibration efforts nor the need. If the full isotopic complexity of $\mathrm{N}_{2} \mathrm{O}$ (bulk, site specific, and clumped isotope values) can be revealed, there is great potential to more accurately evaluate microbial and abiotic $\mathrm{N}_{2} \mathrm{O}$ sources and global budgets of this important greenhouse gas.

\section{Distribution of USGS51 and USGS52}

USGS51and USGS52 $\mathrm{N}_{2} \mathrm{O}$ isotopic reference materials are available from:

U.S. Geological Survey

Reston Stable Isotope Laboratory

431 National Center

12201 Sunrise Valley Drive

Reston, Virginia 20192

USA

http://isotopes.usgs.gov/

Fax: +17036485889

Each distribution unit contains approximately $300 \mu \mathrm{mol}$ of $\mathrm{N}_{2} \mathrm{O}$ in a $6-\mathrm{mm}$ borosilicate glass tube approximately $30 \mathrm{~cm}$ in length. Instructions for transferring $\mathrm{N}_{2} \mathrm{O}$ into instrumentation are given at https://isotopes.usgs.gov/lab/referencematerials/USGS51-USGS52.pdf. 


\section{Acknowledgements}

This work was funded by the National Science Foundation (NSF) Earth Sciences Instrumentation and Facilities program (grant \#1456430), the NSF Geobiology and Low Temperature Geochemistry program (grant \# 1630399), the Japan Society for Promotion of Sciences grant-in-aid (grant \# 17H06105) and the U.S. Geological Survey National Research Program. This material is partly based upon work supported by the U.S. Department of Energy, Office of Science, Office of Biological and Environmental Research under Award Number DE-SC0018409, and work funded by the DOE Great Lakes Bioenergy Research Center (DOE BER Office of Science DE-FC02-07ER64494). Assistance in the laboratory was provided by Stanley Mroczkowski (U.S. Geological Survey) and Matthew Forbes (Stanford University). Any use of trade, firm, or product names is for descriptive purposes only and does not imply endorsement by the U.S. Government. Work at Empa was supported by the European Metrology Programme for Innovation and Research (EMPIR) 16ENV06 project "Metrology for Stable Isotope Reference Standards (SIRS)". The EMPIR initiative is co-funded by the European Union's Horizon 2020 research and innovation programme and the EMPIR Participating States. We greatly appreciate the comments and insights provided by two anonymous reviewers and by Craig Stricker.

\section{REFERENCES}

1. Ostrom NE, Ostrom PH. Mining the isotopic complexity of nitrous oxide: a review of challenges and opportunities. Biogeochemistry 2017; 132: 359-372. doi 10.1007/s10533-017-0301-5

2. Mohn J, Tuzson B, Manninen A, et al. Site selective real-time measurements of atmospheric $\mathrm{N}_{2} \mathrm{O}$ isotopomers by laser spectroscopy. Atmos. Meas. Tech. 2012; 5, 1601-1609. doi:10.5194/amt-5-1601-2012

3. Harris E, Nelson DD, Olszewski W, et al. Development of a spectroscopic technique for continuous online monitoring of oxygen and site-specific nitrogen isotopic composition of atmospheric nitrous oxide. Anal. Chem. 2014; 86: 1726-1734. doi: $10.1021 /$ ac403606u

4. Magyar P, Orphan VJ, Eiler JM. Measurement of rare isotopologues of nitrous oxide by high-resolution multi-collector mass spectrometry. Rapid Commun. Mass Spectrom. 2016; 30: 1923-1940. doi: 10.1002/rcm.7671

5. Young ED, Rumble III D, Freedman P, Mills M. A large-radius high mass-resolution multiple-collector isotope ratio mass spectrometer for analysis of rare isotopologues of $\mathrm{O}_{2}, \mathrm{~N}_{2}, \mathrm{CH}_{4}$ and other gases. International J. Mass Spectrom. 2016; 401: 1-10. doi.org/10.1016/j.ijms.2016.01.006 
6. Friedman L, Bigeleisen J. Oxygen and nitrogen isotope effects in the decomposition of ammonium nitrate. J. Chem. Phys. 1950; 18, 1325-1331. doi.org/10.1063/1.1747471

7. Richardson WS, Wilson Jr EB. The infrared spectrum of $\mathrm{N}^{15} \mathrm{~N}^{14} \mathrm{O}$ and force constants of nitrous oxide. J. Chem. Phys. 1950; 18: 694-696. doi: $10.1063 / 1.1747729$

8. Coplen TB. Normalization of oxygen and hydrogen isotope data. Chem. Geol. 1988; 72: 293-297. doi.org/10.1016/0168-9622(88)90042-5

9. Mohn J, Wolf B, Toyoda S, et al. Interlaboratory assessment of nitrous oxide isotopomer analysis by isotope ratio mass spectrometry. Rapid Commun. Mass Spectrom. 2014; 28: 1995-2007. doi.org/10.1002/rcm.6982

10. Snider DM, Venkiteswaran JJ, Schiff SL, Spoelstra J. From the ground up: Global nitrous oxide sources are constrained by stable isotope values. PloS One. 2015; 10: e0118954. doi.org/10.1371/journal.pone.0149290

11. Cohen ER, Cvitaš T, Holmström B, et al. Quantities, units and symbols in physical chemistry. RSC Publishing, Cambridge, UK, 2014.

https://www.iupac.org/fileadmin/user_upload/publications/e-resources/ONLINEIUPAC-GB3-2ndPrinting-Online-Sep2012.pdf.

12. Brand WA, Coplen TB. Stable isotope deltas: tiny, yet robust signatures in nature. Isot. Environ. Health Stud. 2012: 48: 393-409. doi: 10.1080/10256016.2012.666977.

13. BIPM. The International system of Units (SI). 8th ed.; Organisation Intergouvernementale de la Convention du Mètre; 2006.

http://www.bipm.org/utils/common/pdf/si brochure 8 en.pdf

14. Coplen TB, Kendall C. Preparation and stable isotope determination of NBS 16 and NBS 17 carbon dioxide reference samples: Anal. Chem. 1982; 54: , 2611-2612. doi: 10.1021/ac00251a050

15. Toyoda S, Yoshida N. Determination of nitrogen isotopomers of nitrous oxide on a modified isotope ratio mass spectrometer. Anal. Chem. 1999; 71: 4711-4718. doi: $10.1021 /$ ac9904563

16. Kaiser J, Röckmann T, Brenninkmeijer CAM. Complete and accurate mass spectrometric isotope analysis of tropospheric nitrous oxide. J Geophys Res-Atmos 2003; 108 (D15): 4214. doi.org/10.1029/2003JD003613 
17. Brand WA. PRECON: a fully automated interface for the pre-GC concentration of trace gases in air for isotopic analysis. Isotopes in Environ. Health Studies 1995; 31: 277-284. doi.org/10.1080/10256019508036271

18. Lewicka-Szczebak D, Augustin J, Giesemann A, Well R. (helium incubation and ${ }^{15} \mathrm{~N}$ gas flux method). Biogeosciences 2017; 14: 711-732. doi.org/10.5194/bg-14$711-2017$

19. Röckmann T., Kaiser J, Brenninkmeijer CAM, Brand WA. Gas chromatography/isotope-ratio mass spectrometry method for high-precision position-dependent ${ }^{15} \mathrm{~N}$ and ${ }^{18} \mathrm{O}$ measurements of atmospheric nitrous oxide. Rapid Commun. Mass Spectrom. 2003; 17: 1897-1908. doi.org/10.1002/rcm.1132

20. Brand WA, Coplen TB, Vogl J, Rosner M, Prohaska T. Assessment of international reference materials for isotope-ratio analysis. Pure Appl. Chem. 2014: 86: 425-467. doi.org/10.1515/pac-2013-1023

21. Zhang QL, Chang TL, Li WJ. A Calibrated Measurement of the Atomic-Weight of Carbon, Chin. Sci. Bull. 1990; 35: 290-296. doi: 10.1360/sb1990-35-4-290

22. Brand W.A, Huang L, Mukai H, Chivulescu A, Richter JM, Rothe M. How well do we know VPDB? Variability of $\delta^{13} \mathrm{C}$ and $\delta^{18} \mathrm{O}$ in $\mathrm{CO}_{2}$ generated from NBS19-calcite. Rapid Commun. Mass Spectrom. 2009; 23: 915-926. doi.org/10.1002/rcm.3940

23. Yoshida $\mathrm{N}$, Matsuo S. Nitrogen isotope ratio of atmospheric $\mathrm{N}_{2} \mathrm{O}$ as a key to the global cycle of $\mathrm{N}_{2} \mathrm{O}$. Geochem J. 1983; 17: 231-239.

24. Cliff SS, Thiemens MH. High-precision isotopic determination of the $180 / 160$ and ${ }^{17} 0 /{ }^{16} 0$ ratios in nitrous oxide. Anal. Chem. 1994; 66: 2791-2793. doi: 10.1021/ac00089a031

25. Kaiser J, Hastings MG, Houlton BZ. Röckmann T, Sigman DM. Triple oxygen isotope analysis of nitrate using the denitrifier method and thermal decomposition of $\mathrm{N}_{2}$ O. Anal. Chem. 2007; 79: 599-607. doi: 10.1021/ac061022s

26. Mukotaka A, Toyoda S, Yoshida N, Well R. On-line triple oxygen isotope analysis of nitrous oxide using decomposition by microwave discharge. Rapid Commun. Mass Spectrom. 2013; 27: 2391-2398. doi.org/10.1002/rcm.6698

27. Kim KR, Craig H. Two-isotope characterization of $\mathrm{N}_{2} 0$ in the Pacific Ocean and constraints on its origin in deep water. Nature 1990; 347: 58-61. doi:10.1038/347058a0

28. Westley MB, Popp BN, Rust TM. The calibration of the intramolecular nitrogen isotope distribution in nitrous oxide measured by isotope ratio mass spectrometry. Rapid Commun. Mass Spectrom. 2007; 21, 391-405. doi: $\underline{10.1002 / \mathrm{rcm} .2828}$ 
29. Mohn J, Gutjahr W, Toyoda S, et al. Reassessment of the $\mathrm{NH}_{4} \mathrm{NO}_{3}$ thermal decomposition technique for calibration of the $\mathrm{N}_{2} \mathrm{O}$ isotopic composition. Rapid Commun. Mass Spectrom. 2016; 30: 2487=2496. doi.org/10.1002/rcm.7736

30. Coplen TB. A double focusing, double collecting mass spectrometer for light stable isotope ratio analysis. Int. J. Mass Spectro. Ion Phys. 1973; 11: 37-40. doi.org/10.1016/0020-7381(73)80053-1

31. Böhlke JK, Coplen TB. Interlaboratory comparison of reference materials for nitrogen-isotope-ratio measurements in Reference and intercomparison materials for stable isotopes of light elements (TECDOC 825). International Atomic Energy Agency, Vienna, 1995, pp 51-62.

32. Coplen TB. Guidelines and recommended terms for expression of stable-isotoperatio and gas-ratio measurement results. Rapid Commun. Mass Spectrom. 2011; 25: 2538-2560. doi.org/10.1002/rcm.5129

33. Coplen TB. Reporting of stable hydrogen, carbon, and oxygen isotopic abundances. Pure Appl. Chem. 1994; 66, 273-276.

34. IAEA (International Atomic Energy Agency). Reference Sheet for International Measurement Standards, http://nucleus.iaea.org/rpst/Documents/VSMOW2_SLAP2.pdf

35. Coplen TB. Discontinuance of SMOW and PDB: Nature 1995; 375: 285. doi:10.1038/375285a0

36. Mariotti A. Atmospheric nitrogen is a reliable standard for natural ${ }^{15} \mathrm{~N}$ abundance measurements. Nature 1983; 303: 685-687. doi:10.1038/303685a0

37. Faghihi V, Meijer HAJ, Gröning M. A thoroughly validated spreadsheet for calculating isotopic abundances $\left({ }^{2} \mathrm{H},{ }^{17} \mathrm{O},{ }^{18} \mathrm{O}\right)$ for mixtures of waters with different isotopic compositions. Rapid Commun. Mass Spectrom. 2015; 29: 1351-1356. doi.org/10.1002/rcm.7232

38. Ostrom NE, Ostrom PH. The isotopomers of nitrous oxide: analytical considerations and application to resolution of microbial production pathways. In Handbook of Environmental Isotope Geochemistry, (Ed. M. Baskaran). Springer, New York, 2012, 453-476. 
Table 1. Results of isotopic homogeneity tests of USGS51 and USGS52 nitrous oxide reference materials analyzed by dual-inlet isotope-ratio mass spectrometry at Michigan State University. Samples were selected from each batch of 20 glass tubes and include multiple tubes from some sets (A-C). Set 7 of USGS51 (italicized) was considered an outlier based on an anomalous $S_{\mathrm{P}}$ (site preference) value and was discarded. The averages across each reference material (including multiples) and one-standard deviations (excluding USGS51 set 7) are shown in bold and included in Table 2.

\begin{tabular}{|c|c|c|c|c|c|c|}
\hline Name & Set & $\begin{array}{l}\delta^{15} \mathrm{~N}_{\text {Air-N2 }} \\
(\mathrm{mUr})\end{array}$ & $\begin{array}{l}\delta^{18} \mathrm{O}_{\mathrm{VSMOW}} \\
\text { (mUr) }\end{array}$ & $\begin{array}{l}\delta^{15} \mathrm{~N}^{\alpha} \text { Air-N2 } \\
(\mathrm{mUr})\end{array}$ & $\begin{array}{l}\delta^{15} \mathrm{~N}^{\beta} \text { Air-N2 } \\
(\mathrm{mUr})\end{array}$ & $\begin{array}{l}S_{\mathrm{P}} \\
(\mathrm{mUr})\end{array}$ \\
\hline USGS51 & 1 & +1.25 & +42.05 & +1.84 & +0.65 & +1.19 \\
\hline USGS51 & 2 & +1.28 & +42.08 & +1.80 & +0.75 & +1.05 \\
\hline USGS51 & 3 & +1.23 & +42.00 & +1.72 & +0.72 & +1.00 \\
\hline USGS51 & 4 & +1.24 & +42.04 & +1.81 & +0.66 & +1.15 \\
\hline USGS51 & 5 & +1.28 & +42.11 & +1.77 & +0.77 & +1.00 \\
\hline USGS51 & 6 & +1.22 & +42.02 & +1.73 & +0.69 & +1.04 \\
\hline USGS51 & 7 & +1.28 & +42.14 & +2.17 & +0.39 & +1.78 \\
\hline USGS51 & 8 & +1.28 & +42.12 & +1.81 & +0.74 & +1.08 \\
\hline USGS51 & 9 & +1.27 & +42.08 & +1.81 & +0.71 & +1.11 \\
\hline USGS51 & 10 & +1.24 & +42.06 & +1.83 & +0.64 & +1.19 \\
\hline USGS51 & 11 & +1.26 & +42.07 & +1.81 & +0.70 & +1.11 \\
\hline USGS51 & $12-A$ & +1.27 & +42.13 & +1.77 & +0.75 & +1.02 \\
\hline USGS51 & $12-B$ & +1.25 & +42.01 & +1.76 & +0.72 & +1.04 \\
\hline USGS51 & 13 & +1.28 & +42.07 & +1.80 & +0.74 & +1.06 \\
\hline USGS51 & 14 & +1.26 & +42.05 & +1.76 & +0.75 & +1.01 \\
\hline USGS51 & $15-A$ & +1.30 & +42.16 & +1.77 & +0.82 & +0.95 \\
\hline USGS51 & $15-B$ & +1.24 & +42.04 & +1.77 & +0.71 & +1.05 \\
\hline USGS51 & 16 & +1.24 & +42.01 & +1.80 & +0.67 & +1.13 \\
\hline USGS51 & 17 & +1.24 & +42.03 & +1.76 & +0.71 & +1.05 \\
\hline USGS51 & 18 & +1.27 & +42.08 & +1.82 & +0.70 & +1.12 \\
\hline USGS51 & 19 & +1.26 & +42.02 & +1.81 & +0.70 & +1.11 \\
\hline USGS51 & 20 & +1.29 & +42.12 & +1.80 & +0.76 & +1.05 \\
\hline Average & & $+1.26 \pm 0.02$ & $+42.06 \pm 0.04$ & $+1.79 \pm 0.03$ & $+0.72 \pm 0.04$ & $+1.07 \pm 0.06$ \\
\hline USGS52 & $1-A$ & +0.41 & +41.54 & +12.66 & -11.85 & +24.51 \\
\hline USGS52 & $1-B$ & +0.39 & +41.49 & +12.67 & -11.90 & +24.57 \\
\hline USGS52 & $1-C$ & +0.37 & +41.42 & +12.68 & -11.95 & +24.63 \\
\hline USGS52 & 2 & +0.45 & +41.56 & +12.69 & -11.81 & +24.50 \\
\hline USGS52 & 3 & +0.40 & +41.53 & +12.68 & -11.88 & +24.56 \\
\hline USGS52 & 4 & +0.39 & +41.48 & +12.68 & -11.91 & +24.59 \\
\hline USGS52 & 5 & +0.40 & +41.50 & +12.66 & -11.87 & +24.53 \\
\hline USGS52 & 6 & +0.44 & +41.49 & +12.65 & -11.78 & +24.42 \\
\hline USGS52 & 7 & +0.40 & +41.41 & +12.59 & -11.79 & +24.38 \\
\hline USGS52 & 8 & +0.41 & +41.42 & +12.56 & -11.76 & +24.33 \\
\hline USGS52 & 9 & +0.42 & +41.46 & +12.63 & -11.80 & +24.43 \\
\hline USGS52 & 10 & +0.40 & +41.50 & +12.72 & -11.92 & +24.65 \\
\hline USGS52 & 11 & +0.40 & +41.52 & +12.71 & -11.92 & +24.63 \\
\hline USGS52 & 12 & +0.39 & +41.47 & +12.71 & -11.94 & +24.65 \\
\hline
\end{tabular}




\begin{tabular}{lllllll} 
USGS52 & 13 & +0.39 & +41.54 & +12.78 & -12.01 & +24.79 \\
USGS52 & 14 & +0.42 & +41.57 & +12.71 & -11.87 & +24.58 \\
USGS52 & 15 & +0.38 & +41.48 & +12.65 & -11.90 & +24.54 \\
USGS52 & 16 & +0.43 & +41.54 & +12.75 & -11.90 & +24.65 \\
USGS52 & 17 & +0.41 & +41.54 & +12.71 & -11.90 & +24.61 \\
USGS52 & 19 & +0.38 & +41.53 & +12.74 & -11.98 & +24.71 \\
USGS52 & 20 & +0.40 & +41.53 & +12.78 & -11.98 & +24.76 \\
Average & & $\mathbf{+ 0 . 4 0 \pm 0 . 0 2}$ & $\mathbf{+ 4 1 . 5 0 \pm 0 . 0 5}$ & $\mathbf{+ 1 2 . 6 9} \pm \mathbf{0 . 0 5}$ & $\mathbf{- 1 1 . 8 9} \pm \mathbf{0 . 0 7}$ & $\mathbf{+ 2 4 . 5 7} \pm \mathbf{0 . 1 2}$ \\
\hline
\end{tabular}


Table 2. Interlaboratory comparison of USGS51 and USGS52 $\mathrm{N}_{2} \mathrm{O}$ isotopic measurements. Individual laboratory uncertainties are standard deviations of minimum of three repeated measurements against the laboratory reference gas and do not include any calibration uncertainties of the laboratory reference gas with respect to Air- $\mathrm{N}_{2}$ and VSMOW.

[Laboratory codes: 1, Tokyo Institute of Technology, Yokohama, Japan; 2, Laboratory for Air Pollution \& Environmental

Technology, Dübendorf, Switzerland; 3, Georg-August University Göttingen, Göttingen, Germany; 4, Michigan State University, East Lansing, MI, USA; 5, Stanford University, Stanford, CA, USA; 6, Thünen Institut, Braunschweig, Germany; 7, U.S. Geological Survey, Reston, VA, USA; 8, Max-Planck-Institute for Biogeochemistry, Jena, Germany. DI-IRMS, dual-inlet isotope-ratio mass spectrometry; Spectro., spectroscopy; CF-GC-IRMS, continuous flow - gas chromatography - isotope ratio mass spectrometry; $S_{\mathrm{P}}$, site preference. The set of values shown in bold can be used provisionally for normalizing $\mathrm{N}_{2} \mathrm{O}$ isotopic measurements to improve interlaboratory consistency following the reporting guidelines given in the text.

\begin{tabular}{|c|c|c|c|c|c|c|c|}
\hline $\begin{array}{l}\text { Laboratory } \\
\text { code }\end{array}$ & Name & $\begin{array}{l}\delta^{15} \mathrm{~N}_{\text {Air-N2 }} \\
\text { (mUr) }\end{array}$ & $\begin{array}{l}\delta^{18} \mathrm{O}_{\text {VSMOW }} \\
(\mathrm{mUr})\end{array}$ & $\begin{array}{l}\delta^{15} \mathrm{~N}^{\alpha}{ }_{\text {Air-N2 }} \\
(\mathrm{mUr})\end{array}$ & $\begin{array}{l}\delta^{15} \mathrm{~N}^{\beta}{ }_{\text {Air-N2 }} \\
(\mathrm{mUr})\end{array}$ & $\begin{array}{l}S_{\mathrm{P}} \\
(\mathrm{mUr})\end{array}$ & Methodology \\
\hline 1 & USGS51 & $+1.32 \pm 0.04$ & $+41.23 \pm 0.04$ & $+0.48 \pm 0.09$ & $+2.15 \pm 0.12$ & -1.67 & DI-IRMS \\
\hline 2 & USGS51 & $+1.23 \pm 0.06$ & $+40.97 \pm 0.05$ & $+0.48 \pm 0.17$ & $+1.97 \pm 0.13$ & $-1.49 \pm 0.28$ & Spectro. \\
\hline 3 & USGS51 & $+1.25 \pm 0.13$ & $+41.44 \pm 0.10$ & $+0.34 \pm 0.21$ & $+2.15 \pm 0.22$ & $-1.82 \pm 0.34$ & DI-IRMS \\
\hline 4 & USGS51 & $+1.26 \pm 0.02$ & $+42.06 \pm 0.04$ & $+1.79 \pm 0.03$ & $+0.72 \pm 0.04$ & $+1.07 \pm 0.06$ & DI-IRMS \\
\hline 5 & USGS51 & $+1.34 \pm 0.04$ & $+41.25 \pm 0.04$ & $+0.91 \pm 0.05$ & $+1.77 \pm 0.09$ & $-0.86 \pm 0.11$ & DI-IRMS \\
\hline 6 & USGS51 & +1.31 & +41.56 & -0.03 & +2.66 & -2.69 & $\begin{array}{l}\text { CF-GC-IRMS } \\
\left(\text { in } \mathrm{N}_{2}\right)\end{array}$ \\
\hline 6 & USGS51 & +1.35 & +41.36 & +0.12 & +2.59 & -2.47 & $\begin{array}{l}\text { CF-GC-IRMS } \\
\text { (in Air) }\end{array}$ \\
\hline 7 & USGS51 & $+1.11 \pm 0.03$ & & & & & $\begin{array}{l}\text { DI-IRMS }\left(\mathrm{N}_{2}\right. \\
\text { conversion) }\end{array}$ \\
\hline 8 & USGS51 & $+0.68 \pm 0.07$ & $+41.73 \pm 0.06$ & & & & DI-IRMS \\
\hline Average & USGS51 & $+1.21 \pm 0.21$ & $+41.45 \pm 0.34$ & $+0.59 \pm 0.61$ & $+2.00 \pm 0.65$ & $-1.42 \pm 1.26$ & \\
\hline 1 & USGS52 & $+0.44 \pm 0.02$ & $+40.64 \pm 0.03$ & $+13.52 \pm 0.04$ & $-12.64 \pm 0.05$ & +26.15 & DI-IRMS \\
\hline 2 & USGS52 & $+0.16 \pm 0.10$ & $+40.19 \pm 0.10$ & $+13.60 \pm 0.30$ & $-13.29 \pm 0.13$ & $+26.89 \pm 0.10$ & Spectro. \\
\hline 3 & USGS52 & $+0.50 \pm 0.09$ & $+40.81 \pm 0.07$ & $+12.44 \pm 0.12$ & $-11.39 \pm 0.18$ & $+23.83 \pm 0.25$ & DI-IRMS \\
\hline 4 & USGS52 & $+0.40 \pm 0.02$ & $+41.5 \pm 0.09$ & $+12.69 \pm 0.06$ & $-11.89 \pm 0.07$ & $+24.57 \pm 0.12$ & DI-IRMS \\
\hline
\end{tabular}




\begin{tabular}{llllllll}
5 & USGS52 & $+0.49 \pm 0.04$ & $+40.69 \pm 0.04$ & $+14.28 \pm 0.05$ & $-13.31 \pm 0.09$ & $+27.58 \pm 0.12$ & $\begin{array}{l}\text { DI-IRMS } \\
\text { CF-GC-IRMS } \\
6\end{array}$ \\
USGS52 & +0.60 & +40.62 & +14.31 & -13.12 & +27.43 & $\begin{array}{l}\text { (in N2) } \\
\text { CF-GC-IRMS } \\
\text { (in Air) }\end{array}$ \\
6 & USGS52 & +0.06 & +40.75 & +15.05 & -13.86 & +28.91 & $\begin{array}{l}\text { DI-IRMS (N } 2 \\
\text { conversion) }\end{array}$ \\
7 & USGS52 & $+0.14 \pm 0.04$ & & & & DI-IRMS \\
8 & USGS52 & $-0.15 \pm 0.07$ & $+41.23 \pm 0.06$ & & & & \\
Average & USGS52 & $+0.29 \pm 0.25$ & $+40.80 \pm 0.40$ & $+13.70 \pm 0.93$ & $-12.78 \pm 0.87$ & $+26.48 \pm 1.78$ & \\
\hline
\end{tabular}


Table 3. Evaluation of bulk $\delta^{15} \mathrm{~N}$ values of USGS51, USGS52, and various other $\mathrm{N}$ isotopic reference materials. Measured $\delta^{15} \mathrm{~N}$ values were determined in the current study by laboratory 7 , assuming a value of $+0.43 \mathrm{mUr}$ for IAEA-N1. TokyoTech, MSU-C and NINO are the internal laboratory pure gas $\mathrm{N}_{2} \mathrm{O}$ standards utilized by laboratories 1,4 and 8, respectively (Table 2).

\begin{tabular}{llcccc} 
ID & Compound & $\begin{array}{c}\text { Measured } \\
\delta^{15} \mathrm{~N}_{\text {Air }}(\mathrm{mUr})\end{array}$ & $\mathrm{n}$ & $\begin{array}{c}\text { Reported } \\
\delta^{15} \mathrm{~N}_{\text {Air }}(\mathrm{mUr})\end{array}$ & $\begin{array}{c}\text { Difference in } \\
\delta^{15} \mathrm{~N}_{\text {Air }}(\mathrm{mUr})\end{array}$ \\
\hline IAEA-N1 & $\left(\mathrm{NH}_{4}\right)_{2} \mathrm{SO}_{4}$ & $+0.43 \pm 0.00$ & 5 & $+0.43 \pm 0.07$ & 0.00 \\
IAEA-N2 & $\left(\mathrm{NH}_{4}\right)_{2} \mathrm{SO}_{4}$ & $+20.44 \pm 0.03$ & 2 & $+20.41 \pm 0.12$ & +0.03 \\
NSVEC & $\mathrm{N}_{2}$ & $-2.72 \pm 0.02$ & 4 & $-2.78 \pm 0.04$ & +0.06 \\
USGS51 & $\mathrm{N}_{2} \mathrm{O}$ & $+1.11 \pm 0.03$ & 4 & $+1.26 \pm 0.021$ & -0.21 \\
USGS52 & $\mathrm{N}_{2} \mathrm{O}$ & $+0.14 \pm 0.04$ & 4 & $+0.40 \pm 0.021$ & -0.30 \\
TokyoTech & $\mathrm{N}_{2} \mathrm{O}$ & $-2.68 \pm 0.01$ & 2 & -2.39 & -0.29 \\
MSU-C & $\mathrm{N}_{2} \mathrm{O}$ & $-1.22 \pm 0.01$ & 2 & $-0.93 \pm 0.10$ & -0.29 \\
NINO & $\mathrm{N}_{2} \mathrm{O}$ & $+0.28 \pm 0.01$ & 2 & $+0.32 \pm 0.08$ & -0.04 \\
& & & & & \\
\hline
\end{tabular}

${ }^{1}$ From Table 1 
